\title{
Variations in the recruitment of syntactic knowledge contribute to SES differences in syntactic development* - ERRATUM
}

\author{
KATHRYN A. LEECH, MEREDITH L. ROWE AND \\ Y I TING HUANG
}

doi: ro.ror7/So3050009ı60002ro, published online by Cambridge University Press, 7 June 2016.

In the original published version of this paper, the co-author Yi Ting Huang was incorrectly credited as 'Yi Huang'. The Press apologises for this mistake and any inconvenience it may have caused.

\section{REFERENCE}

Leech, K. A., Rowe, Meredith, L., and Huang, Yi Ting. (2016). Variations in the recruitment of syntactic knowledge contribute to SES differences in syntactic development. Fournal of Child Language. Published online 7 June 2013, doi: I0.1017/So3050009 I60002 Io. 